\title{
Ulcerative colitis and Sweet's syndrome: A case report and review of the literature
}

\author{
Massud Ali MD, Donald R Duerksen MD
}

\begin{abstract}
M Ali, DR Duerksen. Ulcerative colitis and Sweet's syndrome: A case report and review of the literature. Can J Gastroenterol 2008;22(3):296-298.

A 47-year-old man with a history of ulcerative colitis on prednisone and azathioprine was admitted to the hospital with a four-day history of fever, skin rash, arthralgias and leukocytosis. A skin biopsy demonstrated neutrophilic infiltration of the dermis that was consistent with Sweet's syndrome. He improved after several days with an increase in his prednisone and azathioprine. Sweet's syndrome is a rare cutaneous manifestation of inflammatory bowel disease, with approximately 40 cases reported in the literature. In a previously reported case of a patient with ulcerative colitis-associated Sweet's syndrome who was on azathioprine at the time of the skin eruption, the azathioprine was stopped, raising the possibility of drug-induced Sweet's syndrome. In the present case, the azathioprine was actually increased with complete resolution of the skin manifestations. This would support the theory that immunosuppressive therapy is the mainstay of therapy for this condition. In conclusion, Sweet's syndrome is a neutrophilic dermatosis that is rarely associated with ulcerative colitis. It may occur while on immunosuppressive therapy and responds to an intensification of immunosuppression.
\end{abstract}

Key Words: IBD; Rash; Sweet's syndrome; Ulcerative colitis

Sweet's syndrome, or acute febrile neutrophilic dermatosis was first described in 1964 by Robert Douglas Sweet (1). It is an uncommon disorder characterized by abrupt onset of fever, elevated white blood cell count, and a painful red, papular skin rash, with a neutrophilic infiltrate of the upper dermis on histology (2). Sweet's syndrome usually improves with systemic corticosteroid treatment. It is associated with malignancies (particularly hematological), infections, inflammatory bowel disease (IBD), pregnancy and drugs such as granulocyte colony-stimulating factor (3). Its association with IBD was described in 1988 (4) and it is considered to be a rare cutaneous manifestation of IBD, with approximately 40 cases reported in the literature.

In the present report, we describe a patient with ulcerative colitis who developed manifestations of Sweet's syndrome while on immunosuppressive therapy. He responded to an intensification of his immunosuppressive regime. The association between Sweet's syndrome and IBD, as well as the role of immunosuppressive therapy for this condition will be discussed.

\section{CASE PRESENTATION}

A 47-year-old Caucasian man presented to the hospital with a four-day history of abrupt onset fever, maculopapular skin rash, arthralgias, generalized malaise and leukocytosis. The skin rash was mildly painful but not pruritic.

\section{La colite ulcéreuse et le syndrome de Sweet : Un rapport de cas et une analyse bibliographique}

\begin{abstract}
Un homme de 47 ans atteint de colite ulcéreuse qui prenait de la prednisone et de l'azathioprine a été hospitalisé parce que, depuis quatre jours, il souffrait de fièvre, d'éruption cutanée, d'arthralgies et de leucocytose. Une biopsie cutanée a démontré une infiltration à neutrophiles du derme, compatible avec un syndrome de Sweet. L'état du patient s'est amélioré au bout de quelques jours, après l'augmentation des doses de prednisone et d'azathioprine. Le syndrome de Sweet est une manifestation cutanée rare des maladies inflammatoires de l'intestin, environ 40 cas ayant été déclarés dans les publications. Dans le cas déjà déclaré d'un patient atteint d'un syndrome de Sweet associé à la colite ulcéreuse qui prenait de l'azathioprine au moment de l'éruption cutanée, le traitement a été interrompu, ce qui soulève la possibilité d'un syndrome de Sweet induit par le médicament. Dans le présent cas, la dose d'azathioprine a été accrue et a donné lieu à la résolution complète des manifestations cutanées. Cette observation appuie la théorie selon laquelle la thérapie immunosuppressive constitue le pilier de la thérapie de cette maladie. En conclusion, le syndrome de Sweet est une dermatose à neutrophiles rarement associée à la colite ulcéreuse. Elle peut se produire pendant une thérapie immunosuppressive et réagit à une intensification de l'immunosuppression.
\end{abstract}

His past medical history indicated that he was diagnosed in 1991 with ulcerative colitis, which was treated with 5-aminosalicylic acid. In the year before his admission, he had several flares that required short courses of prednisone. Two weeks before his admission, a colonoscopy demonstrated active ulcerative colitis, particularly in his left colon. He was treated with prednisone $20 \mathrm{mg} /$ day and, given his need for corticosteroids over the previous year, was started on azathioprine $100 \mathrm{mg} /$ day. At the time of his admission, his colitis had improved but he was still having six to eight bowel movements per day and occasionally had blood in his stool.

Upon physical examination, he was febrile with a body temperature of $39.5^{\circ} \mathrm{C}$. The skin examination revealed erythematous, papular plaques over his scalp, face, trunk, and upper and lower extremities (Figure 1). There was no lymphadenopathy or signs of arthritis.

Laboratory examination revealed a white blood cell count of $27.6 \times 10^{9} / \mathrm{L}$ with $96 \%$ neutrophils. Renal and liver function tests were normal. Blood cultures were negative. A swab for culture and sensitivity from the skin lesions was negative. C3, C4, rheumatoid factor, circulating antineutrophil cytoplasmic antibody, perinuclear antineutrophil cytoplasmic antibody and antinuclear antibody tests were negative. A computed tomography scan of the abdomen did not reveal any obvious pathology except for changes consistent with colitis of the left colon.

Department of Internal Medicine, University of Manitoba, Winnipeg, Manitoba

Correspondence: Dr Donald R Duerksen, University of Manitoba, 409 Taché Avenue, Winnipeg, Manitoba R2H 2 A6.

Telephone 204-237-2796, fax 204-233-7154, e-mail duerksn@cc.umanitoba.ca

Received for publication August 14, 2007. Accepted August 23, 2007 

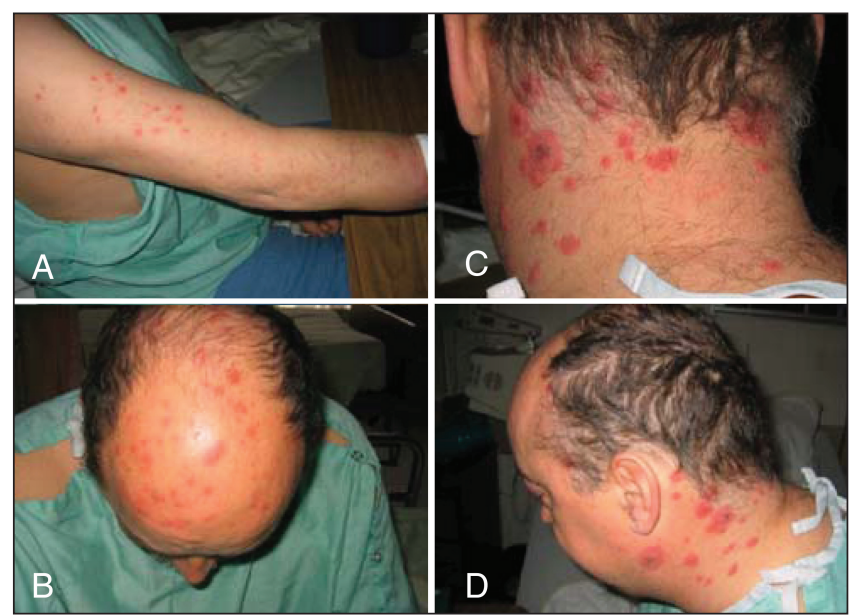

Figure 1) Erythematous plaque-like skin rash on the upper arm (A), the scalp (B), the base of the neck (C) and the neck (D)

A skin biopsy of a macular nodule on his right forearm revealed a neutrophilic infiltrate in the dermis and subcutaneous tissues (Figure 2). The infiltrate was primarily in the superficial dermis, was perivascular and was associated with mild extravasation of red blood cells. There was no evidence of vasculitis present.

The dose of prednisone was increased from $15 \mathrm{mg}$ to $30 \mathrm{mg}$ once per day, and azathioprine was increased from $100 \mathrm{mg}$ to $150 \mathrm{mg}$ once per day. Within a few days, the patient's fever subsided and cutaneous lesions improved. His ulcerative colitis also went into remission. Over three years of follow-up examinations, there was no recurrence of Sweet's syndrome or flare of his ulcerative colitis.

\section{DISCUSSION}

Based on the presentation of acute painful erythematous plaques, histological evidence of a dense dermal neutrophilic infiltrate (without vasculitis) and associated fever, and neutrophilia, as well as the response to increased corticosteroid therapy, the present patient fulfilled the diagnostic criteria for Sweet's syndrome (5).

Unlike erythema nodosum or pyoderma gangrenosum, Sweet's syndrome is a rare cutaneous manifestation of ulcerative colitis or Crohn's disease. There have been approximately 40 cases of Sweet's syndrome and IBD reported in the literature - only 15 of these have been associated with ulcerative colitis $(2,6-10)$. Sweet's syndrome associated with IBD tends to be more common in women ( $87 \%)$ and is usually associated with active disease (2).

In the past, it was believed that the association between an uncommon disorder like Sweet's syndrome and a relatively common disease like IBD was by chance only, but given the increasing number of case reports on Sweet's syndrome and IBD (IBD is now the third most common disease associated with Sweet's syndrome [3]), this is unlikely. The other factor supporting a true association between Sweet's syndrome and IBD is that Sweet's syndrome is from the same family of cutaneous disorders (the neutrophilic dermatoses) as erythema nodosum and pyoderma gangrenosum, suggesting a possible common pathogenesis. Patients with IBD-associated Sweet's syndrome may also have manifestations of pyoderma gangrenosum $(11,12)$ and erythema nodosum $(13)$.
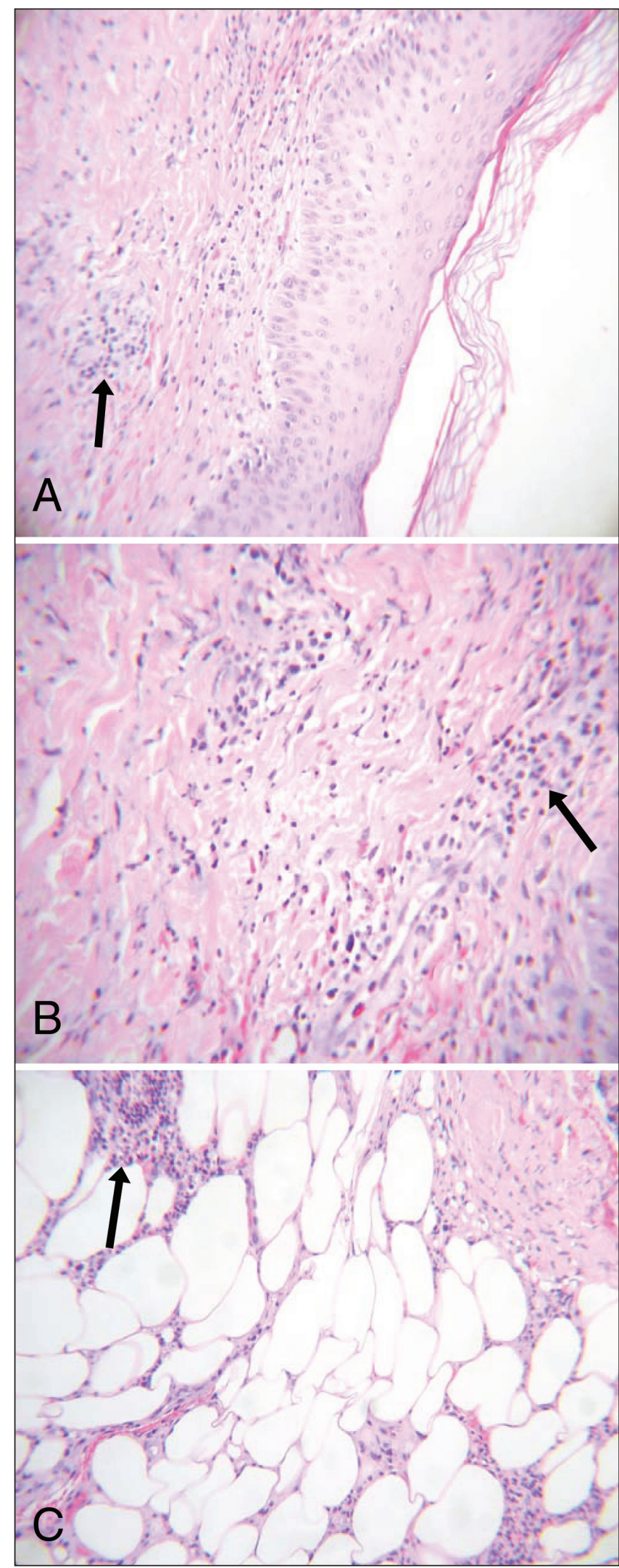

Figure 2) Skin biopsy of a macular nodule. A Neutrophilic infiltration (arrow) of the superficial dermis tissue (low-power magnification, hematoxylin and eosin stain). B Neutrophilic infiltration (arrow) of the superficial dermis tissue (high-power magnification, hematoxylin and eosin stain). C Neutrophilic infiltration (arrow) of the subcutaneous tissue (low-power magnification, hematoxylin and eosin stain) 
All of the reported cases of IBD and Sweet's syndrome have had colonic involvement and only 20\% of patients with Crohn's disease had ileal involvement in addition to their colonic disease (2,6-10). This raises the possibility that there is a relationship between colonic bacteria or antigens and the pathogenesis of Sweet's syndrome, but the precise mechanisms underlying the pathogenesis of this condition are unclear. Most of the reported patients are women (87\%), unlike other cutaneous manifestations of IBD, which have no sex differences. The presence of extraintestinal symptoms, such as joint symptoms and other skin rashes, is frequent in patients with IBD-associated Sweet's syndrome (11).

The temporal relationship between Sweet's syndrome and IBD activity is variable, and it can present before the diagnosis of IBD (20\%), at the time of diagnosis (28\%) or after the diagnosis of IBD (52\%) (11). Patients have presented with Sweet's syndrome as long as 19 years after the initial diagnosis of IBD. Although Sweet's syndrome was diagnosed in four patients with inactive disease (two patients with Crohn's disease and two with ulcerative colitis), the occurrence of the syndrome is more common in active disease. There has been one report of Sweet's syndrome occurring after a proctocolectomy for ulcerative colitis (12).

Sweet's syndrome may be associated with medications (3). Antibiotics that have been associated with Sweet's syndrome include minocycline, trimethoprim and sulfamethoxazole, and nitrofurantoin. In addition, there is a recent report of Sweet's

\section{REFERENCES}

1. Sweet RD. An acute febrile neutrophilic dermatosis. Br J Dermatol 1964;76:349-56.

2. Ytting H, Vind I, Bang D, Munkholm P. Sweet's syndrome - an extraintestinal manifestation in inflammatory bowel disease. Digestion 2005;72:195-200.

3. Cohen PR, Kurzrock R. Sweet's syndrome revisited: A review of disease concepts. Int J Dermatol 2003;42:761-78.

4. Kemmett D, Gawkrodger DJ, Wilson G, Hunter JA. Sweet's syndrome in Crohn's disease. BMJ 1988;297:1513-4.

5. Walker DC, Cohen PR. Trimethoprim-sulfamethoxazoleassociated acute febrile neutrophilic dermatosis: Case report and review of drug-induced Sweet's syndrome. J Am Acad Dermatol 1996;34:918-23.

6. Paoluzi OA, Crispino P, Amantea A, et al. Diffuse febrile dermatosis in a patient with active ulcerative colitis under treatment with steroids and azathioprine: A case of Sweet's syndrome. Case report and review of literature. Dig Liver Dis 2004;36:361-6.

7. Vazquez J, Almagro M, del Pozo J, Fonseca E. Neutrophilic pustulosis and ulcerative colitis. J Eur Acad Dermatol Venereol 2003;17:77-9. syndrome in a Crohn's disease patient believed to be due to ofloxacin (14). The case presented in the present paper was unique because the manifestations of Sweet's syndrome developed while the patient was on immunosuppressive therapy. In another case of ulcerative colitis and Sweet's syndrome with a patient on azathioprine (6), the azathioprine was stopped, raising the possibility of drug-induced Sweet's syndrome. In the present case, the azathioprine was actually increased with complete resolution of the skin manifestations. This would support the theory that immunosuppressive therapy is the mainstay of therapy for this condition and that azathioprine is not associated with Sweet's syndrome.

The most effective treatment of Sweet's syndrome is immunosuppressive therapy, most frequently with systemic corticosteroids. Other reported treatment modalities include colchicine, indomethacin, clofazemine, cylcosporin and dapsone (3). Recently, there have been reports of patients with Crohn's disease and Sweet's syndrome responding to immunosuppressive therapy with infliximab $(8,9)$.

\section{CONCLUSIONS}

Sweet's syndrome is a neutrophilic dermatosis disorder that is rarely associated with ulcerative colitis and Crohn's disease of the colon. This extraintestinal manifestation of IBD may occur while patients are on immunosuppressive therapy and responds to an intensification of the immunosuppressive regime.

8. Foster EN, Nguyen KK, Sheikh RA, Prindiville TP. Crohn's disease associated with Sweet's syndrome and Sjogren's syndrome treated with infliximab. Clin Dev Immunol 2005;12:145-9.

9. Rahier JF, Lion L, Dewit O, Lambert M. Regression of Sweet's syndrome associated with Crohn's disease after anti-Tumour Necrosis Factor therapy. Acta Gastroenterol Belg 2005;68:376-9.

10. Rjeibi I, Zeglaoui F, El Fekih N, Ezzine N, Fazaa B, Kamoun MR. [Sweet's syndrome: Report of 5 cases.] Rev Med Liege 2006;61:834-6.

11. Travis S, Innes N, Davies MG, Daneshmend T, Hughes S. Sweet's syndrome: An unusual cutaneous feature of Crohn's disease or ulcerative colitis. The South West Gastroenterology Group. Eur J Gastroenterol Hepatol 1997;9:715-20.

12. Benton EC, Rutherford D, Hunter JA. Sweet's syndrome and pyoderma gangrenosum associated with ulcerative colitis. Acta Derm Venereol 1985;65:77-80.

13. von den Driesch P, Gomez RS, Kiesewetter F, Hornstein OP. Sweet's syndrome: Clinical spectrum and associated conditions. Cutis 1989;44:193-200.

14. Ozdemir D, Korkmaz U, Sahin I, et al. Ofloxacin induced Sweet's syndrome in a patient with Crohn's disease. J Infect 2006;52:e155-7. 


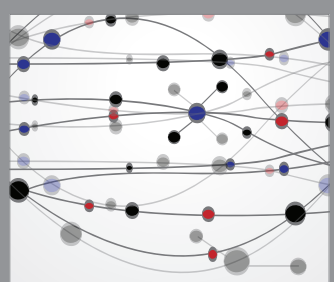

The Scientific World Journal
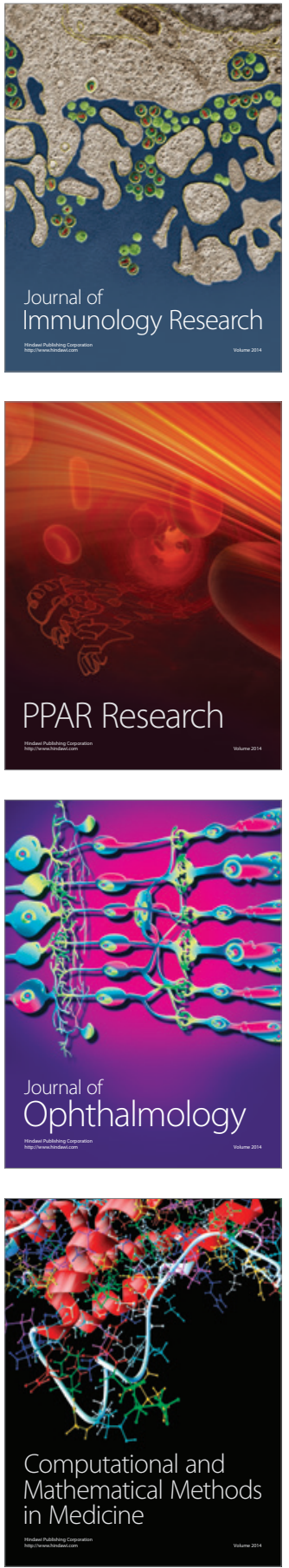

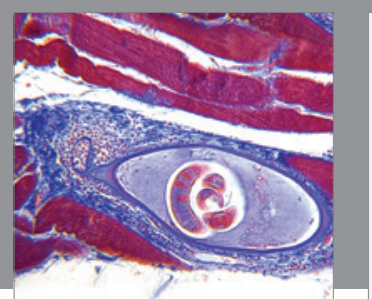

Gastroenterology Research and Practice

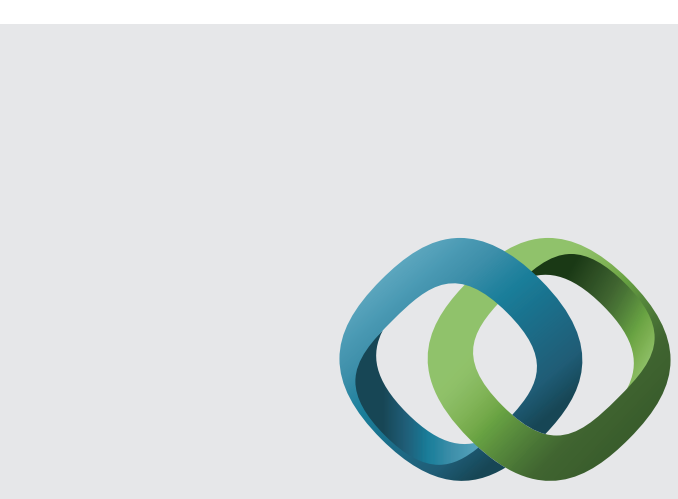

\section{Hindawi}

Submit your manuscripts at

http://www.hindawi.com
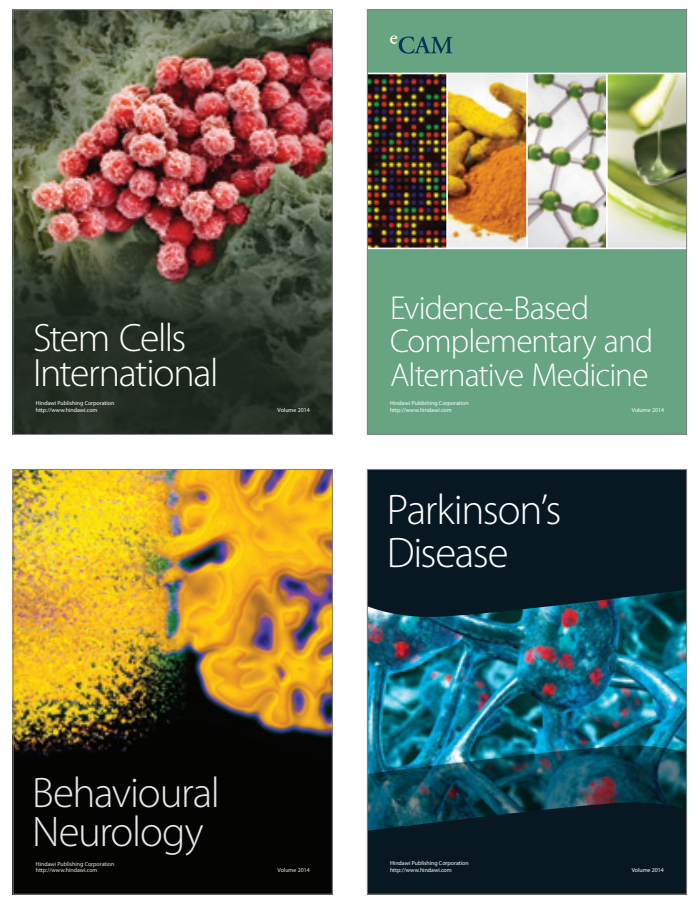
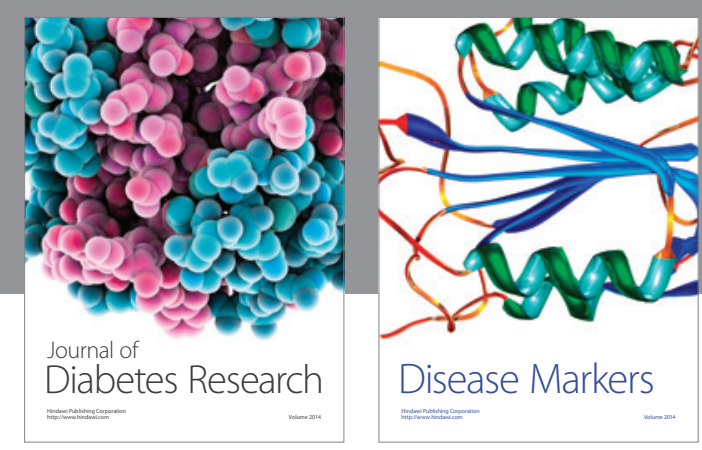

Disease Markers
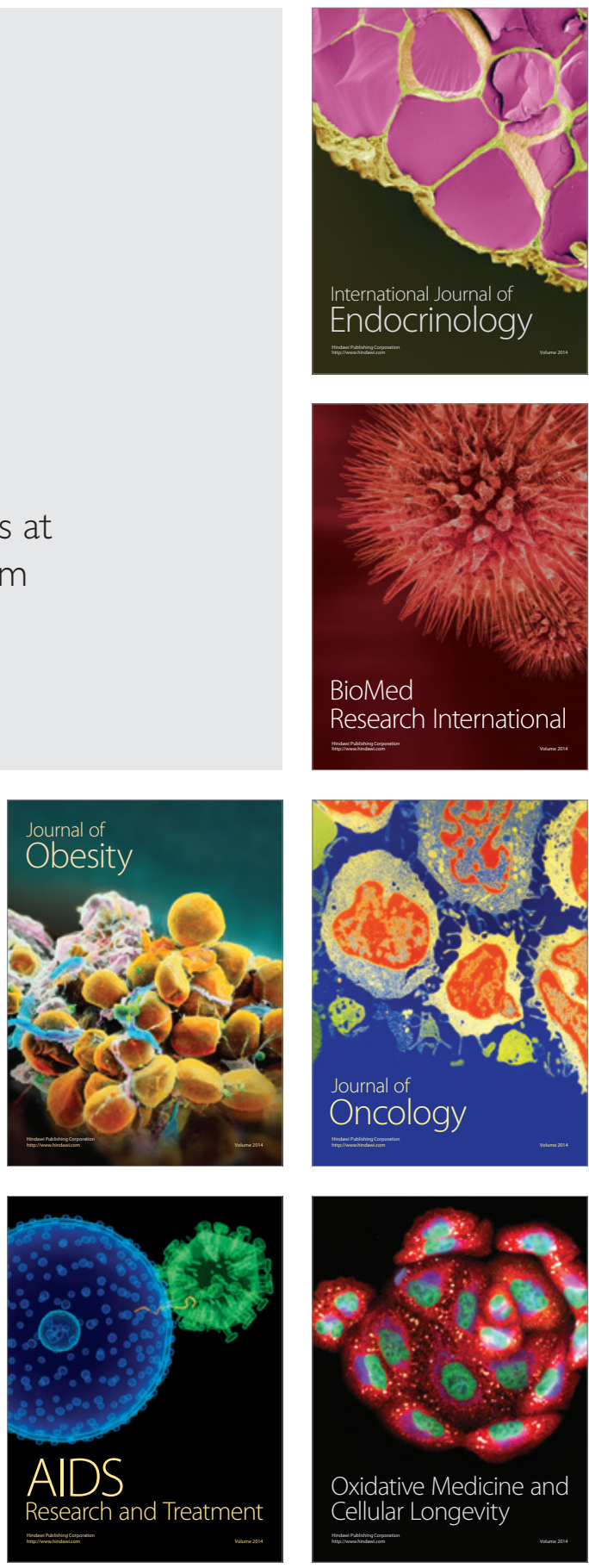